\title{
INSTILLING BELIEF VALUES AMONG ADOLESCENTS
}

\section{KHWATER MUSA FADLALLA MOHAMMED}

Assistant Professor, Department of Islamic Studies, College of Education, Majmaah University, Saudi Arabia

This research focuses on the values of faith and ethics based on the importance of civilization and human values in society as an important engine of the actions performed by the individual in his environment, affecting and affected by the relationship to social life.

In addition to the importance of orientation to the generation of adolescents, as a social group with their needs and requirements, as well as, the value of their composition has a decisive impact on the quality of their social and economic performance now and in the future, because they are a social and economic force expected by the community, to be an appropriate input to the search. In addition to that, family, the media, and schools have a huge role in cultivating the moral values and beliefs of adolescents, and this will be discussed specifically in this research.

KEYWORDS: Ethics, Adolescents, Civilizational \& Values of Faith
\end{abstract}

Received: Mar 05, 2018; Accepted: Mar 26, 2018; Published: May 18, 2018; Paper Id.: IJESRJUN201815

\section{INTRODUCTION}

One of the foundations of the civilization formation of societies is social relations, as social cohesion is an important necessity of social advancement. The social discipline of the members of the society of different classes and interests, and their fields of work ensures the preservation of the community with human relations intact, free of anomalies and behavioral deviation, Therefore, there must be institutions that play the role of social upbringing (Katila, 2017).

Today's values contribute to the formation of people's lives in terms of their relationship with God, and between each other and organizing it, as well as values is the first brick in building the personality of the individual and assert itself, its cultural identity, and positive adaptation to the conditions of life to perform its desired cultural role, where the Qur'an and Sunnah are the values that regulate human life in all cases.

Islamic values have a separate nature of other values, as they stem from the Islamic faith in a fundamental way, not from temporary interest. It makes human the basis of all values, and is aimed at the interest of the human that does not stop at this limited life, but extends into the afterlife (Attia, \& Al-Hashimi, 2008).

The instilling of values in adolescents is one of the main goals that education must be concerned with. The individual who loses his values loses his balance and values of society as the pillars of construction that carry the entire building. So, instilling values are important for both individual and social at the same time.

The adolescence stage is one of the most important stages in which the crystallization of the personality is developed. It is a dynamic biological and psychological stage, so the interest in the teenager's growing moral and emotional thinking must be increased because adolescence increases the ability to control behavior other than 
childhood. Depending on the growth of moral behavior, so the adolescent shows an interest in what is right and keen on moral knowledge and ethical conduct (Shakshak, 2010).

\section{Research Objectives}

The basic aim of this study is to:

\section{Clarify the Way and Importance of Instilling Belief Values among Adolescents}

Research sub-aims are

1. Study the impact of the media, teachers, and the family in instilling the values of faith in adolescents.

2. Recognize the types of Islamic values that have been provided to adolescents.

3. Study the impact of instilling belief values among adolescents in society.

\section{Research Questions}

This research aims to ask the following questions:

1. What is the impact of the media, teachers, and the family in instilling the values of faith in adolescents?

2. What are the types of Islamic values that have been provided to adolescents?

3. What is the impact of instilling belief values among adolescents in society?

\section{Research Significance}

Educational values represent the basis of all the other areas of Islamic educational values, it includes an overlaps with them in many things. The faith aspect represented by the educational values of faith is the most important aspect of Islamic education and its deepest impact. The first goal is to prepare the believing human who worships God in all matters of his life in order to achieve the ultimate goal of human creation. Despite its importance, this does not mean that it is the only aspect of Islamic education because it is comprehensive and aims to form the human personality in all its aspects; faith, moral, political, military, social, and economic.

The study tackled the important role played by the media, schools, and family in strengthening moral and faith values at an important age (adolescence). This sensitive stage plays a pivotal role in shaping the future of the society and its values, preparing them for life in different dimensions.

Conditions which are experienced by the Islamic nation in its contemporary life is not a normal danger; it is a great danger that every scene should be aware of and take care of. What is seen daily and what is heard about it in many countries in general and Islamic countries, especially the high rates of crime, and sometimes even murder, all this and other clear signs of a decline in the system of ethics and values, especially in the era of globalization and openness to the West.

Based on the above, and because adolescence is one of the most vulnerable periods, the researcher finds that there is an urgent need to research ways to protect adolescents from the danger of previous challenges, and strengthen their faith.

\section{FAITH VALUES AND THE IMPORTANCE OF IMPLANTATION IT IN ADOLESCENTS}

The concept of values is a common concept in everyday life, and there is no single definition recognized by all researchers. But in general, values are considered the image of society, because it is the basis of individual-social behavior, 
and in general, society does not build without the existence of this normative structure.

Values derived from the Holy Quran and Sunna are obligatory for Muslims and they are obliged to apply its principles and standards. These values are constant and do not change with circumstances, because their basic criterion is constant, which is the strengthening of God. Within these values, the standards of behavior and etiquette of the people were determined. Their relations were based on cooperation, brotherhood, consultation, equality, respect, and good character (Ben Mustafa \& Essays, 2014).

There is an increasing interest studying of values during recent decades by specialists in all branches of the humanities, and perhaps one of the factors behind it, the role played by values and their impact in most aspects of society and institutions, especially educational institutions (Khatib, 2002).

The education and faith values are the greatest characteristic of societies and individuals and have an important role in directing behavior at the level of the individual and community. Values directed all individual's for the better, which reflects positive impacts on human personality, and thus to the society through his interactions. If these values embodied in the individual's personality, it will become an instrument and director of behavior (Abu-Daf, 2011).

Each personality has its own characteristics that distinguish it, and there are different positive features can be found in these personalities. So, it is important to guide these basic characteristics, compliment them, highlight the positive aspects, and link them to the faith side, so that the motivation of these characteristics is the motive of faith. Perfection, honesty, modesty, and generosity are examples of faith, values (Ali, 2010), figure [1] shows other different core values.

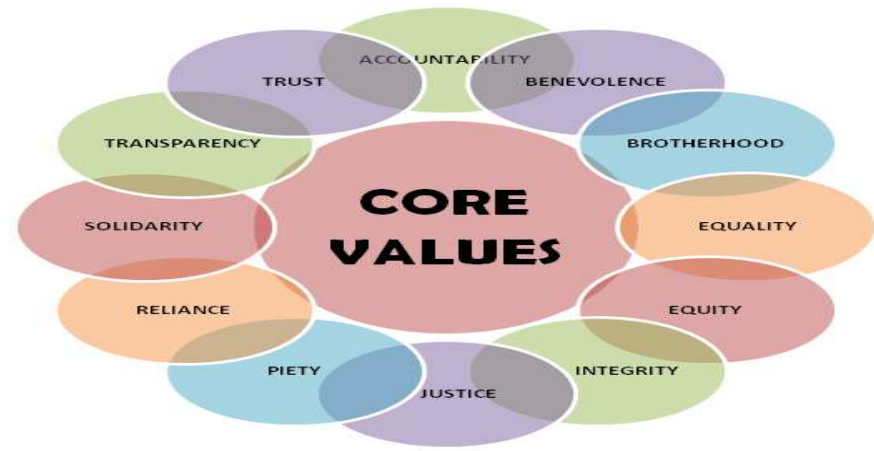

Figure 1: Core Faith Values (Katila, 2017)

Adolescence is a period of transformation and change in all areas of physical, emotional, cognitive and social development. It is also a stage of great transformation of morals and ethical standards. Al-Zu'bi (2013) stated that a teenager is clearly interested in rituals and religious rituals in adolescence, where his faith is transformed from the quoted faith into religious vigilance.

Ghabari and Abu Shaira (2010) point out that morality is based on religion, even if it is, it will be a shallow, superficial morality, because religion is the strongest foundation on which a person's moral and behavior can be based. Thus, morals based on religion are inherent in personality and are linked to the basis of their being and their heart.

\section{THE ROLE OF THE FAMILY IN INSTILLING FAITH VALUES}

The family is defined with respect to an Islamic view as a group of individuals connected to a divine bond of bondage, blood or alliance, to achieve the purpose that God desires from them, living under one roof, and united by 
common interests (Al-Hamd, 2002).

The family is the most important medium that instills Islamic educational values. It is the first incubator of human beings. As well as, the longest life period in human's life, so he infused with ethics, morals, ideas, attitudes, and traditions. Therefore the family is either a good source of building a religion, morals, and good values or degrade it.

In terms of seniority, a family is the oldest social institution known and plays its important role in educating children and enriching them with expertise, skills, and values (Abu Daif \& Najem, 2005).

The importance of family in instilling faith, values represented in several fields (Salami, 2011):

- Faith Field: by recitation of children to remember the greatness of God and His grace, and to deduce the unity through the effects of His power, to warn children against falling into polytheism and to explain the basic concepts of heaven and hell, life and death, angels, and books, taking into consideration the gradation according to the age of the children, in addition to family's role in correcting the children's faith, giving them positive attitudes, such as responding to God and obeying him and thanking him for his grace, and showing the children the truth of faith in the Prophet and instilling his love in their hearts.

- Spiritual Field: Emphasis on the principle of slavery of God and its results, teaching and urged children to pray. Also, children must be linked to the Koran and reciting it.

- Moral Field: The role of the family is determined in the instigation and development of the virtues of manners that Islam has affirmed in terms of sincerity, humility, patience, honesty, kindness, life and other morals, as well as the disintegration of children and students from immoral behavioral practices of lying, cheating, and other negative behaviors acquired through intermingling with others (Hamza, 2011).

- Physical Field: Parents must encourage their children to take care of the body's cleanliness, to sleep, to wake up early, and to teach them sports exercises to strengthen their bodies.

- Social Field: By teaching children to return to peace in their Islamic way, teach them the ethics of in-house permission before and after puberty, instructing them to respect adults, to guide children towards mixing with others and not being introverted, setting their own standards, giving adult children the concepts and principles of a married life, visualizing their goals and ingredients, and preparing them to be good husbands in the future.

- Educational and Cultural Fields: ensure that children are aware of the importance of academic excellence and diligence in seeking knowledge, Explain the virtue of science and scientists through the Quran and Sunnah, follow up school lessons and home works with children, encourage them to do it through explanation and clarification, encourage children to self-read for all that is useful, which contributes to the development of their culture, and to monitor what is presented to children through all types of media (Zu'bi, 2013).

Thus, the family has a strong influence on its children in the development and implantation of Islamic educational values, and the adolescent's relationship with others is influenced by the attitudes of the parents. They are an example that learns from their actions more than they learn from their words to respect for others and their rights or learn not to confine such respect to those who belong to the same level of social or color or religion. 


\section{THE ROLE OF THE TEACHER IN INSTILLING FAITH VALUES}

The teacher is an important intermediary to convey information to his students, as the person who directs and conducts the learning process. There is no doubt that one of the most important factors behind the attention to the process of educational learning and the establishment of educational institutions is ,in fact, the interest of the community to transfer its knowledge and values to the new generation; for this, teacher was one of the most important foundations of this public interest; because the representative of the community and responsible for the transfer of its heritage of knowledge and values (Allam, 2010).

The role of the teacher as a teacher and educator extends beyond teaching activity to many other aspects of activity such as educational, psychological, social, religious and professional guidance, and directing parents to the best of their children's education. All various types of guidance are one of the core works of the teacher as his presence helps him in a position to observe their behavior (Qashlan, 2010).

The school and teacher have an important role in educating the correct educational values for students, based on Islamic principles, Summarized in the following (Qashlan, 2010):

- Revitalize and consolidate the unity of the learners and enrich their experiences with their Monotheism-based.

- Developing the scientific thinking of the learners at various stages, especially in adolescence, and training them in applying it, and benefiting from it in facing the problems that they encounter.

- Teach adolescents healthy habits related to body health, such as cleanliness and attention to nutrition, exercise and avoiding harmful behaviors such as smoking, alcohol abuse, drugs, etc.

- Educating learners to cherish their Islamic religion and their desire to adhere to their teachings through their behavior in the changing reality of life in many aspects of God's instructions.

- Teach adolescents the necessary jurisprudential provisions related to worship and transactions, in a simple and easy way that links the scientific material with their practical reality (Zu'bi, 2013).

- Promoting the learner's passion through its focus on a fundamental corner of the love of God, it nourishes the souls of the sincere in love with affection, mercy, and enlightenment, and sets the strong foundation for the development of emotional participation among Muslims. The beginning lies in the regularity of learner sentiment and the love of others and sympathy with them, in addition, it is necessary for the school to refine learner ideas of illusions and inhibitions of the pessimism, as well as training them to be moderate in their emotions.

- Develop the innovative, creative aspect of learners, so that the school should shift from teaching based on memorization and verbal control to learning that develops learners' imagination, taste, creativity, analyzing.

The importance of the school as an educational institution that instills values among students is therefore important. It is therefore, the responsibility of the administrators and officials to develop and update all aspects of the school and to provide all the services and provide them with the means that will enhance the educational and the educational process and ensure its continuity. 


\section{THE ROLE OF MEDIA IN INSTILLING FAITH VALUES}

Media is a medium of Islamic educational values; it plays a serious and important role in the lives of the people in general, and in the life of the adolescent in particular, it has occupied a very important position, so that it has often become an alternative to the book and many institutions of education.

The media include all possible means and equipment to convey the written, audible or audiovisual message to the public. The media include all the tools and means to convey the written, audiovisual or public message to the public. Many media outlets, such as newspapers, magazines, radio, television, Internet, and mobile phones, have now spread (Zu'bi, 2013).

Media has a great ability to influence significant in the life of society, shaping it, change and guide people's lives in a large way, because of its modern technologically advanced capabilities. Islamic media can play a very important educational and faith's role, which encompasses multiple fields of life and is reflected positively in the lives of the individual and the community. The effects of the media can be summed up as follows (Helis \& Mahdi, 2010):

- Contribute to the development of concepts, facts, values, and true faith orientations derived from the Qur'an and Sunnah of Prophet Muhammad and to work on the purification of individuals from myths, illusions, and ideologies that contradict the doctrine of unification, and to emphasize the importance of the link between faith and work.

- To work on eradicating religious illiteracy by explaining the pillars of Islam, identifying the reality of religion, understanding the deviations of reality from the curriculum of God, spreading Islamic culture, showing positive effects on the life of the individual and society, and showing their effective role in building the Muslim personality.

- Disseminate and develop various important information and knowledge, and work on acquiring diverse sciences and knowledge.

There is an urgent need to pay close attention to the programs of these means and the philosophy on which they are based. So that it must be consistent with the nature of the society and its culture and needs. They should not be factors that encourage crime, deviation, corruption, especially among young people and adolescent.

\section{CONCLUSIONS}

The faith, values are the personality of the strong, balanced individual cohesive, because they follow fixed principles and values, as it strengthens his will, and organize his elements, by unifying the destination, and a person who is immoral and wobbly feels self-dispersed and plagued by psychological conflicts.

To ease the process of instilling values, it must be started at the childhood, as implanting values in childhood is easier than planting them later. Many parents do not care about instilling values until they begin to suffer the problems of their son or daughter in adolescence.

The school is one of the most important educational institutions with great influence in instilling values and faith in adolescents; it guides their behavior and modifies their intentions and attitudes. The school is undoubtedly the most important environment for students after their family to learn ethics, so the values and ethics must be the basis of the basic 
knowledge of the teenager gets from school.

One of the most dilemma reasons for the perplexing of a Muslim teenager today is the contradiction in the society in which he lives, a contradiction between what he has inherited and what he lives in, and between what he teaches from various sources, such as media, school, and family, and between what religious scholars demand.

\section{REFERENCES}

1. Abu Daif, M. \& Najem, M. (2005). Assessing the Role of the Palestinian Family in Child Education in the Light of the Sunnah, presented to the Palestinian Children's Conference, College of Education, Islamic University, Gaza.

2. Abu-Daf, M. (2011). Educational Communication in Sunnah, An Analytical Study presented to the Conference of Dialogue and Educational Communication towards a Better Palestinian Society, Faculty of Education, Islamic University, Gaza.

3. Ali, S. (2010). Origins of Islamic Education, 2nd, Dar Al-Masirah for Publishing and Printing, Amman.

4. Allam, R. (2010). Research Methods in Psychological and Educational Sciences, Dar Al-Nashr for Universities, Cairo.

5. Attia, M. \& Al-Hashimi, A. (2008). Practical Education and its Applications in the Preparation of the Future Teacher, Dar AlMaagheh for Publishing and Distribution, Amman.

6. Ben Mustafa, M. \& Essays, T. (2014). Moral judgment and its relation to the level of optimism and pessimism among Yarmouk University students, Jordanian Journal of Educational Sciences, v.10, No.4.

7. Ghubari, T. \& Abu Shuaira, K. (2010). Sociology of Human Growth between Children and Adolescents, Arab Society Library for Publishing and Distribution, Amman.

8. Hamad, A. (2002). Islamic Education, Dar Ashbiliya, Riyadh.

9. Hamza, A. (2010). How to raise our children, House of Culture for Publishing and Distribution, Amman.

10. Srivastava, SK, and Naveen Pant. "Social Support and Achievement Motivation among Adolescents."

11. Helis, M. \& Mahdi, N. (2010). The Role of the Media in Forming Social Awareness among Palestinian Youth, Al-Azhar University Journal, Gaza, Human Sciences Series, Volume 12, Issue 2

12. Katila, F. (2017). Moral Thinking among Adolescent Adolescents at the Secondary School, Qasidi Marbah Ouargla University, Algeria.

13. Thakur, Ghanshayam, and Dinesh Kumar Lahari. "A Study of Psychological Impact on Physical Health and Fitness among Adolescents."

14. Khatib, M. (2002). The role of universities in the development of values among students, a survey of the views of forensic science teachers and educational science teachers, Zarqa National University, Jordan, p.2.

15. Qashlan, A. (2010). The role of secondary school teachers in promoting the Islamic values of their students in the portfolios of Gaza, Al-Azhar University, Gaza.

16. Salami, S. (2011). Educational Implications derived from Al-Tahrim for Prohibition and its Application in Contemporary Family Reality, Islamic and Comparative Education Department, Umm Al-Qura University, Makkah.

17. Shakshak, A. (2010). Teenager personality Problems and Solutions, Shuaa fprPublishing and Science, Aleppo.

18. Zu'bi, A. (2013). The Psychology of Adolescence, Theories of Growth, Problems and Treatment, Dar Zahran, Amman. 
